\title{
Depression and dry eye: a narrative review
}

\author{
Gabriela César Falcão Vieira1 (1), Bruna Rachel de Oliveira Rodrigues² (1), \\ Carlos Eduardo Ximenes da Cunha ${ }^{3 *}$ (1) , Gabriella Bento de Morais ${ }^{4}$ (1), \\ Luiz Henrique Ribeiro de Moraes Ferreira' ${ }^{1}$, Marina Viegas Moura Rezende Ribeiro ${ }^{3}$
}

\begin{abstract}
SUMMARY
Dry eye disease (DED) is a multifactorial disease affecting tear quality and/or production and eye surface and is one of the most common eye disorders found in clinical practice. The association between psychiatric disorders and dry eye has been the subject of several studies since patients with this syndrome present a tendency toward a depressive mood. This narrative review aims to demonstrate the relationship between depression and DED, which is due to the side effects of psychotropic drugs or the tendency of the low pain threshold of the depressive patient. The work was produced from the analysis of 13 articles published during the last decade on this subject and demonstrated that the depressive state is linked to the appearance or worsening of DED resulting from chronic eye pain. Also, the treatment of depression with selective inhibitors of serotonin receptors causes inflammatory cytokine secretion with subsequent inflammation and apoptosis of cells on the ocular surface. The need for new studies on optimization of psychiatric treatment in patients with ophthalmic diseases, such as DED, was verified, aiming at the relief of symptoms and the reduction of psychological and eye damage caused by them. KEYWORDS: Dry eye. Depression. Ophthalmology. Psychiatry.
\end{abstract}

\section{INTRODUCTION}

Dry eye disease/syndrome (DED) is a multifactorial disease that affects tear quality and/or production and the surface of the eye ${ }^{1}$. It is one of the most common eye disorders and is characterized by symptoms of eye discomfort, such as pain, dryness, foreign body sensation, visual disorders, and tear film instability ${ }^{2}$. The discomfort caused by this disease diminishes the quality of life not only concerning vision but also about daily activities in general, which tend to become impaired ${ }^{3}$.
The association of DED with psychiatric disorders has already been the subject of several studies ${ }^{4}$. It has been reported that individuals with this syndrome present an increased risk for psychological stress, severe anxiety, and depression ${ }^{4}$. It has been suggested that a predisposition of DED patients to depression exists since their symptoms, such as visual blur induced by tear film instability, can worsen depressive moods ${ }^{5}$.

In addition, previous studies have indicated that drugs prescribed for psychiatric conditions can precipitate $\mathrm{DED}^{6-8}$.

\footnotetext{
${ }^{1}$ Faculdade Nova Esperança - João Pessoa (PB), Brazil.

${ }^{2}$ Centro Universitário Faculdade de Ciências Sociais Aplicadas - Campina Grande (PB), Brazil.

${ }^{3}$ Centro Universitário de João Pessoa - João Pessoa (PB), Brazil.

${ }^{4}$ Centro Universitário Tiradentes - Maceió (AL), Brazil.

*Corresponding author: ocaduximenes@gmail.com

Conflicts of interest: the authors declare there are no conflicts of interest. Funding: none.

Received on December 04, 2020. Accepted on December 13, 2020.
} 
Most antidepressant drugs have antagonistic effects on muscle receptors, which can cause adverse effects, including DED ${ }^{9,10}$.

In this sense, this study aimed to explain the relationship between the depressive state and DED either through the psychological stress generated by the eye picture or by psychotropic drugs used for the treatment of depression.

\section{METHODOLOGY}

This study was formatted as a literature review concerning the association between depression and signs of suicide (SOS). Articles written from 2010 to 2020 were selected from the LILACS, SCIELO, and MEDLINE databases, both in Portuguese and English, using the keywords "dry eyes syndrome", "xerophthalmia", and "depression" in addition to their corresponding English terms, "dry eyes syndromes", "xerophthalmia", and "depression" using AND/OR as operators. we established the relationship: "dry eyes syndromes OR xerophthalmia AND depression".

Adding all of the databases, we found 254 articles, 15 of which were used after reading their abstracts. The inclusion criteria consisted of several parameters:

(1) articles available in full on the internet;

(2) articles published in English and Portuguese;

(3) those that demonstrate a direct relationship between DED and depression;

The exclusion criteria included several parameters:

(1) thesis;

(2) monograph;

(3) non-scientific resources;

(4) articles whose full texts were not available;

(5) texts that did not present significant content on the proposed theme based on reading the abstracts.

\section{RESULTS}

Depression and DED are distinct disorders that are related in their pathophysiology and treatment (Table 1). Thus, the analyzed studies state that chronic eye pain is associated with the development of anxiety, depression, and loss of sleep quality in patients.

In addition, the treatment of depression with selective serotonin receptor inhibitors results in DED due to activation of the nuclear factor kappa beta (NF-kB) pathway that leads to inflammation and apoptosis of cells on the ocular surface. In this scenario, a study showed the participation of inflammatory cytokines, interleukin-7, and tumor necrosis factor alpha (IL-7 and TNF- $\alpha$, respectively) in the instability of tear film.
Furthermore, the neurotrophic factor levels derived from the brain may be altered in patients with depression since this is the factor responsible for alterations in the secretion of the lacrimal gland and the appearance of DED.

\section{DISCUSSION}

\section{Relationship between dry eye syndrome and depression}

DED causes numerous unpleasant symptoms and directly affects the quality of life of individuals who have $\mathrm{it}^{3}$. As a result of DED, patients with this syndrome present themselves with the most depressed mood in relation to those with depression ${ }^{4,11}$. In addition, it is important to emphasize that in major depression, it is common to have a relationship between these psychic conflicts and organ disorders (somatization), one example being depression and $\mathrm{DED}^{10,11}$.

A study by Galor et al. ${ }^{6}$ with patients who were seen in an ophthalmology clinic aimed to evaluate the relationship between dry eye symptoms, non-ocular conditions, and lacrimal film parameters from standardized questionnaires and tests for measuring the lacrimal film ${ }^{6}$. As a result, it was concluded that non-ocular conditions, such as post-traumatic stress disorder and non-ocular pain, are more significantly associated with dry eye symptoms than the parameters of the tear film, which is one of the signs for the diagnosis of this syndrome ${ }^{6}$.

Another study performed by Hallak et $\mathrm{al}^{7}$ in which cases of patients with DED and control individuals were compared aimed at determining the association between depressive symptoms and $\mathrm{DED}^{7}$. The data for this weighting were obtained from the evaluation of depressive symptoms using the Beck Depression Inventory ${ }^{7}$. As a result of this research, it was determined that DED symptom scores and depression scores were significantly different between cases and controls ${ }^{6,7}$. The established chance ratio was 2.79 in a $95 \%$ confidence interval ${ }^{7}$. Thus, this study provides further evidence on the association between DED and depression?

In addition, research by Tiskaoglu et al. ${ }^{3}$ also aimed to evaluate the association between depression and $\mathrm{DED}^{3}$. However, this time, patients diagnosed with depression had their data compared to the control group ${ }^{3}$. The following parameters were considered for the index of eye surface diseases:

(1) visual function questionnaires;

(2) tear break time;

(3) vital eye surface staining; and

(4) Schirmer's test, which evaluates whether the eye produces enough tears to remain lubricated ${ }^{3}$. 
Table 1. Analysis of studies that signaled the influence of depression in patients with dry eye syndrome (DED).

\begin{tabular}{|c|c|}
\hline Author & Study summary \\
\hline $\begin{array}{l}\text { Tiskauglu N.S. } \\
\text { et al. } 2017^{3}\end{array}$ & The study shows the association between depression and dry eye syndrome (DED). \\
\hline Nepp J. $2016^{4}$ & Patients with dry eye that is resistant to drug therapy often have symptoms of anxiety and depression. \\
\hline $\begin{array}{l}\text { Han S.B. et al. } \\
2017^{5}\end{array}$ & $\begin{array}{l}\text { The study reviews the main pathological and neurological conditions related to dry eyes, such as } \\
\text { anxiety, depression, post-traumatic stress, chronic pain, and peripheral neuropathy. }\end{array}$ \\
\hline $\begin{array}{l}\text { Galor A. et al. } \\
2015^{6}\end{array}$ & $\begin{array}{l}\text { Dry eye symptoms in patients are more related to non-ocular pain and } \\
\text { depression than to alterations in the tear film. }\end{array}$ \\
\hline $\begin{array}{l}\text { Hallak J.A. } \\
2015^{7}\end{array}$ & $\begin{array}{l}\text { The study consisting of } 53 \text { patients with dry eye showed the association between } \\
\text { dry eye pathology and the appearance of depressive symptoms. }\end{array}$ \\
\hline $\begin{array}{l}\text { Koçer E. et al. } \\
2015^{8}\end{array}$ & $\begin{array}{l}\text { A study with } 57 \text { control subjects using antidepressants proved the relationship between the use of } \\
\text { selective serotonin receptor inhibitors and a higher risk of dry eye development in these patients. }\end{array}$ \\
\hline $\begin{array}{l}\text { Zhang X. et al. } \\
2019^{9}\end{array}$ & $\begin{array}{l}\text { Selective serotonin reuptake inhibitors cause dry eye via activation of the NF-kB pathway, which is } \\
\text { associated with inflammation and apoptosis of cells on the ocular surface. }\end{array}$ \\
\hline $\begin{array}{l}\text { Wen W. et al. } \\
2012^{10}\end{array}$ & $\begin{array}{l}\text { DED is common in patients with depression and anxiety, especially in the elderly, } \\
\text { with longer diagnostic times and in use of selective serotonin receptor inhibitors. }\end{array}$ \\
\hline $\begin{array}{l}\text { Weatherby } \\
\text { T.J.M. et al. } \\
2019^{11}\end{array}$ & $\begin{array}{l}\text { A metanalysis with } 22 \text { studies showed a direct relationship between } \\
\text { the severity of dry eye and the development of depression and anxiety. }\end{array}$ \\
\hline $\begin{array}{l}\text { Acan D. et al. } \\
2016^{12}\end{array}$ & $\begin{array}{l}\text { A study of } 72 \text { patients showed a possible relationship between } \\
\text { selective serotonin receptor inhibitors and tear film instability. }\end{array}$ \\
\hline $\begin{array}{l}\text { Mrugacz et al. } \\
2017^{13}\end{array}$ & $\begin{array}{l}\text { Lacrimal secretion samples were collected from } 32 \text { controls with depression using psychotropics that } \\
\text { showed the participation of inflammatory cytokines, interleukin-7, and tumor necrosis alpha (IL-7 and } \\
\text { TNF- } \alpha \text {, respectively) in the development of dry eye in these patients. }\end{array}$ \\
\hline $\begin{array}{l}\text { Sano K. et al. } \\
2019^{14}\end{array}$ & $\begin{array}{l}\text { The neurotrophic factor levels derived from the brain can be altered in patients with depression since } \\
\text { this factor is responsible for alterations in lacrimal gland secretions. }\end{array}$ \\
\hline $\begin{array}{l}\text { Wu M. et al. } \\
2019^{15}\end{array}$ & $\begin{array}{c}\text { Poor sleep quality, anxiety, and depression are conditions associated with decreased secretion of the } \\
\text { tear gland and instability of the tear film. }\end{array}$ \\
\hline
\end{tabular}

Author: Cunha, CEX. (2020) The pathophysiological processes illustrated above were described by Zhang X. et al..9; Acan D. et al..12; Mrugacz et al. ${ }^{13}$; Sano K. et al. ${ }^{14}$, (Adapted).

Comparison of cases and controls revealed significantly lower scores for Schirmer's test and tear breakage time in the depressive group ${ }^{3}$. This finding indicates a higher propensity of this group of patients to develop $\mathrm{DED}^{3}$.

\section{Selective serotonin reuptake inhibitor} treatment causes increased levels of lacrimal serotonin, severe inflammatory response, and cell apoptosis on the ocular surface

To explore the performance of the selective serotonin reuptake inhibitors (SSRI) in DED associated with depression, serotonin and inflammatory cytokine levels in tears were analyzed ${ }^{8,9}$.

An enzyme-linked immunosorbent assay (ELISA) results showed that patients undergoing SSRI treatment had higher levels of lacrimal serotonin than controls $(2.66 \pm 0.63 \mathrm{ng} / \mathrm{mL}$ versus $1.18 \pm 0.33 \mathrm{ng} / \mathrm{mL}, \mathrm{p}<0.01)^{9}$.
Analysis of the protein chip revealed even more cytokines after the use of SSRI, based on the examination of 507 proteins, including Toll-like receptor 4 and interleukins- 6 and 10 (TLR4, IL-6, and IL-10, respectively) were found'. TLR4 was detected exclusively in patients treated with SSRI as confirmed by $\mathrm{qRT}-\mathrm{PCR}(\mathrm{p}<0.01)^{9}$.

The qRT-PCR assay demonstrated that the inflammatory cytokine genes for TNFa, IL1b, and IL10 and the pro-apoptotic gene AIF, BAD, and BAX levels increased in the SSRI group, while the levels of the anti-apoptotic gene BCL2 and XIAP decreased in this same group $(\mathrm{p}<0.01)^{9}$.

Serotonin induces inflammation and cellular apoptosis by activating the NF-jB pathway, thus indicating that this pathway is closely related to serotonin and regulatory effects on inflammation and cellular apoptosis ${ }^{9}$. (Figure 1) To understand whether NF-jB was actually involved, a specific NF-jB 
signaling inhibitor (JSH-23) was used in cells treated with SSRI ${ }^{12}$. The Western Blot assay demonstrated changes in the level of expression of P-p65, IjBa, the pro-inflammatory response element TLR4, and the inflammatory cytokine IL-1b. Western blotting also demonstrated that the pro-apoptotic proteins $\mathrm{BAX}, \mathrm{BAD}$, and AIF were all reversed in the corneal epithelial cells treated with JSH-239 .

The ELISA assay showed that the IL-1b and IL-10 levels increased and TNF $\alpha$ content in the cell supernatant was reversed by the NF-jB signaling inhibitor $(\mathrm{p}<0.01)^{9}$.

In addition, a decrease in cell apoptosis was observed after cells were treated with JSH-23 of cells along with a concurrent increase in serotonin levels $(\mathrm{p}<0.01)^{13}$.

These data suggest that the use of SSRI aggravates DED associated with depression and causes intensification of the response to inflammation in addition to cellular apoptosis on the ocular surface, revealing that a higher level of lacrimal serotonin is the main cause of inflammation and apoptosis of corneal epithelial cells ${ }^{8,9,13}$. (Figure 1) These results showed that serotonin regulated the inflammatory response and cellular apoptosis through the activation of NF-jB signaling thus corroborating that there is more evidence about the serotonin/ nuclear factor (HT/NF-jB) axis in DED that is associated with depression ${ }^{3,9}$. This finding provides a new strategy for clinical treatment in the face of this clinical condition?.

Two major challenges in the management of dry eye exist:

(1) diagnosis, whose exams often do not correlate with clinical results;
(2) treatment, mainly because conventional therapy with artificial tears is not sufficient in moderate to severe cases of dry eye ${ }^{7,3,9}$.

\section{Selective serotonin reuptake inhibitors aggravate dry eye associated with depression}

In the study, to verify the behavior of the SSRI in the DED associated with depression, an SSRI was offered to the cases of depressive rats over a period of 3 or 6 weeks ${ }^{9}$. It was observed that the corneal staining scores gradually increased along with the levels of lacrimal serotonin in the SSRI group $(\mathrm{p}<0.01)$, while no difference in lacrimal secretion was found between the two groups $(\mathrm{p}>0.05)^{9}$.

Corneal staining also showed that the staining was diffuse and progressively intense in the SSRI group ${ }^{7,9}$. qRT-PCR, immunohistochemical staining, and ELISA results showed that the levels of IL-1b, TNF $\alpha$, and TLR 4 increased significantly in the SSRI group $(\mathrm{p}<0.01)^{9}$. In addition, normal rats were subject to SSRI for a period of 3 or 6 weeks, and it was found that the content of 5-HT, IL-1b, and TNF- in tears increased similarly $(\mathrm{p}<0.01)^{11}$.

These data demonstrate that SSRI cause progressive damage to the corneal epithelium and DED, as they increase lacrimal serotonin levels ${ }^{9,7}$. The findings showed that depression could cause a decrease in lacrimal secretion and an increase in production of IL- $1 \mathrm{~b}$ and TNF $\alpha$ in rats with a close association between DED and depressive symptoms?

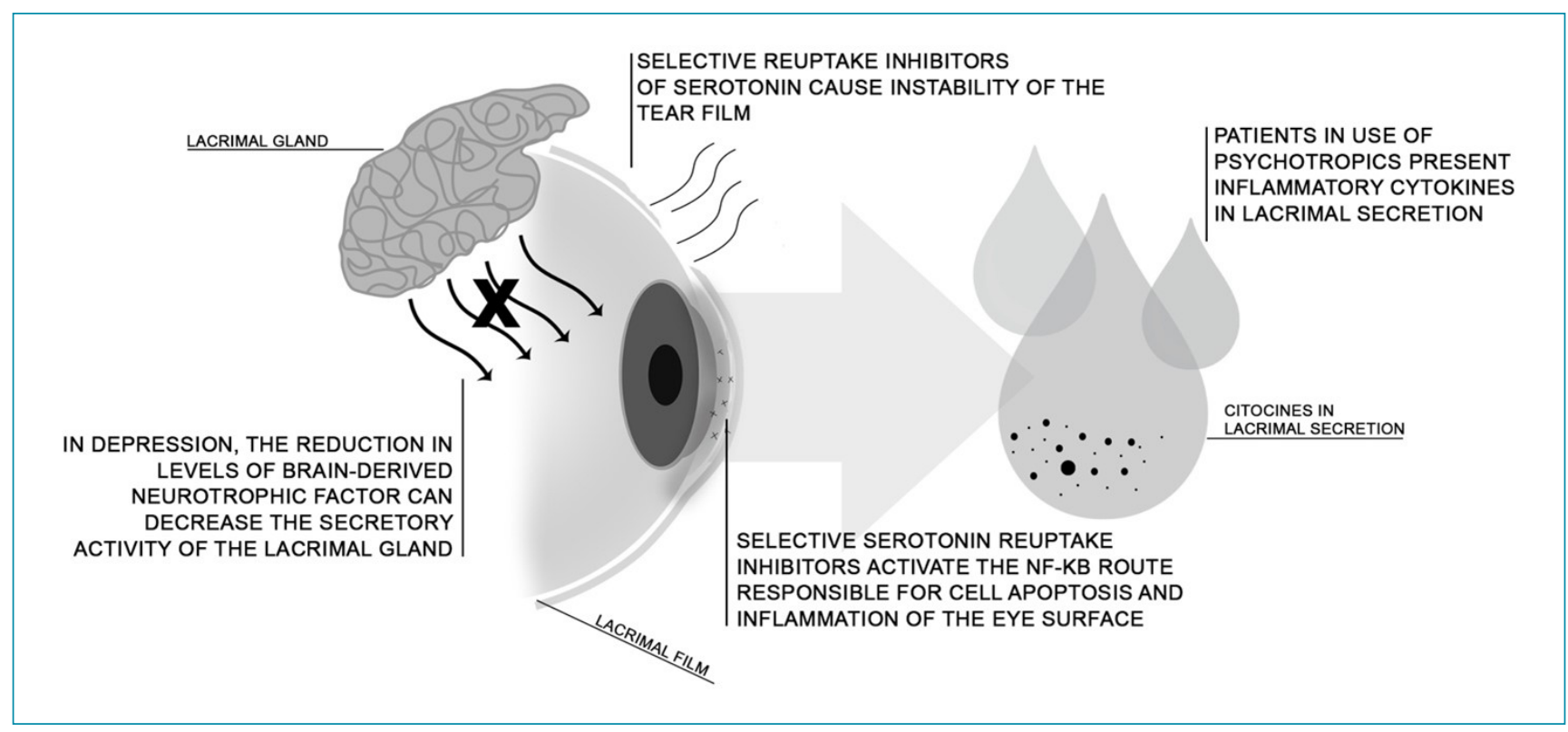

Figure 1. Relation between depression and dry eye disease (DED). 


\section{Prospects of therapy for dry eye syndrome in patients with depression}

The participation of ophthalmologists and psychiatrists in the treatment of people with Dry Eye Syndrome can be highly favorable ${ }^{11}$. DED intervention can help reduce manifestations of depression, and in addition to providing appropriate therapy for depressive symptoms can cooperate in reducing DED symptoms since these symptoms are closely linked and interfere with people's quality of life $e^{4,5,11}$.

Treatment goals that may serve as a principle in the study of therapies for DED correlating to depression in human beings in the future have been suggested ${ }^{11,14}$. The idea exists that psychological and physical stress causes a decrease in the secretion of tears, and to evaluate this association, a reference of stress DED mice was instituted ${ }^{14}$. In the research study, the enriched environment (EE), which presents additional cognitive, sensory, and social stimuli, was an influence to act to alleviate the stress-induced decline in the amount of tears ${ }^{14}$.

EE succeeded in increasing the expression of the brain-derived neurotrophic factor (BDNF) in rats; in contrast, the stress load caused a decrease in the expression of this factor? An animal model was employed, but the intervention can also relieve symptoms in humans ${ }^{9}$. (Figure 1) The results indicate that BDNF is correlated with DED disease'. Therapy consists of relieving the symptom of dry eye using supplementary eye drops; however, a treatment that acts on the underlying pathology is necessary ${ }^{7,9}$. Two conditions that help in the success of the treatment are the practice of physical exercise in addition to a sense of well-being ${ }^{14,15}$.

The most common reports from patients with DED are dryness (45\%), foreign body sensation (24\%), and tired eyes $(15 \%)^{15}$. More than half of the patients had obtained inadequate quality sleep when compared to the control group, and the group with DED had a shorter duration of sleep and a higher depression score ${ }^{9,15}$. The study indicated that mood and sleep are closely related to DED and an improvement in these two aspects could be linked to good therapy ${ }^{15}$.

\section{CONCLUSION}

It is observed that the depressive state is linked to the appearance or worsening of DED resulting from chronic eye pain in the patient resulting. Given the above findings, the need to search for new ways to optimize the psychiatric treatment of patients with ophthalmic diseases, such as DED, to relieve symptoms and the reducing damage with broad therapeutic success.

\section{AUTHORS' CONTRIBUTIONS}

MVMRR: Supervision. GCFV: Writing - Review \& Editing. LHRMF: Writing - Review \& Editing. CEXC: Writing Review \& Editing. GBM: Writing - Review \& Editing. BROR: Writing - Review \& Editing.

\section{REFERENCES}

1. Clayton JA. Dry eye. N Engl J Med. 2018;378(23):2212-23. https://doi.org/10.1056/NEJMra1407936

2. Ribeiro MMR, Timbó F, Ribeiro E, Ribeiro LE. Os efeitos a longo prazo do uso de concentrado de plaquetas em olho seco diabético: uma série de casos. Rev Bras Oftalmol. 2019;78(1):42-5. https://doi.org/10.5935/0034-7280.20190009

3. Tiskaoglu NS, Yazıcı A, Karlıdere T, Sari E, Oguz EY, Musaoglu $M$, et al. Dry eye disease in patients with newly diagnosed depressive disorder. Curr Eye Res. 2017;42(5):672-6. https:// doi.org/10.1080/02713683.2016.1236966

4. Nepp J. Psychosomatische aspekte beim trockenen auge. Ophthalmologe. 2016;113(2):111-9. https://doi.org/10.1007/ s00347-015-0187-3

5. Han SB, Yang HK, Hyon JY, Wee WR. Association of dry eye disease with psychiatric or neurological disorders in elderly patients. Clin Interv Aging. 2017;12:785-92. https://doi.org/10.2147/CIA.S137580

6. Galor A, Felix ER, Feuer W, Shalabi N, Martin ER, Margolis TP, et al. Dry eye symptoms align more closely to non-ocular conditions than to tear film parameters. Br J Ophthalmol. 2015;99(8):1126-9. https://doi.org/10.1136/bjophthalmol-2014-306481
7. Hallak JA, Tibrewal S, Jain S. Depressive symptoms in patients with dry eye disease: a case-control study using the beck depression inventory. Cornea. 2015;34(12):1545-50. https:// doi.org/10.1097/ICO.0000000000000641

8. Koçer E, Koçer A, Özsütçü M, Dursun AE, Krpnar I. Dry eye related to commonly used new antidepressants. J Clin Psychopharmacol. 2015;35(4):411-3. https://doi.org/10.1097/ JCP.0000000000000356

9. Zhang $X$, Yin $Y$, Yue L, Gong L. Selective serotonin reuptake inhibitors aggravate depression-associated dry eye via activating the NF-KB pathway. Invest Ophthalmol Vis Sci. 2019;60(1):40719. https://doi.org/10.1167/iovs. 18-25572

10. Wen $W$, Wu Y, Chen $Y$, Gong L, Li M, Chen X, et al. Dry eye disease in patients with depressive and anxiety disorders in Shanghai. Cornea. 2012;31(6):686-92. https://doi.org/10.1097/ ICO.0b013e3182261590

11. Weatherby TJM, Raman VRV, Agius M. Depression and dry eye disease: a need for an interdisciplinary approach? Psychiatr Danub. 2019;31(Suppl 3):619-21. PMID: 31488802 
12. Acan $D$, Kurtgoz P. Influence of selective serotonin reuptake inhibitors on ocular surface. Clin Exp Optom. 2017;100(1):83-6. https://doi.org/10.1111/cxo.12415

13. Mrugacz M, Ostrowska L, Bryl A, Szulc A, Zelazowska-Rutkowska B, Mrugacz G. Pro-inflammatory cytokines associated with clinical severity of dry eye disease of patients with depression. Adv Med Sci. 2017;62(2):338-44. https://doi.org/10.1016/j. advms.2017.03.003
14. Sano K, Kawashima M, Imada T, Suzuki T, Nakamura S, Mimura $M$, et al. Enriched environment alleviates stress-induced dry-eye through the BDNF axis. Sci Rep. 2019;9(1):3422. https://doi. org/10.1038/s41598-019-39467-w

15. Wu M, Liu X, Han J, Shao T, Wang Y. Association between sleep quality, mood status, and ocular surface characteristics in patients with dry eye disease. Cornea. 2019;38(3):311-7. https://doi.org/10.1097//CO.0000000000001854 